\title{
Sensitivity and specificity of NT-proBNP to detect heart failure at post mortem examination
}

\author{
Sara Sabatasso • Paul Vaucher • Marc Augsburger • \\ Nicolas Donzé • Patrice Mangin • Katarzyna Michaud
}

Received: 24 October 2010 / Accepted: 2 May 2011 /Published online: 20 May 2011

(C) The Author(s) 2011. This article is published with open access at Springerlink.com

\begin{abstract}
NT-proBNP, a marker of cardiac failure, has been shown to be stable in post mortem samples. The aim of this study was to assess the accuracy of NT-proBNP to detect heart failure in the forensic setting. One hundred sixty-eight consecutive autopsies were included in the study. NTproBNP blood concentrations were measured using a chemiluminescent immunoassay kit. Cardiac failure was assessed by three independent forensic experts using macro- and microscopic findings complemented by information about the circumstances of body discovery and the known medical story. Area under the receiving operator curve was of $65.4 \%$ (CI 95\%, from 57.1 to 73.7 ). Using a standard cut-off value of $>220 \mathrm{pg} / \mathrm{mL}$ for NT-proBNP blood concentration, heart failure was detected with a sensitivity of $50.7 \%$ and a specificity of $72.6 \%$. NTproBNP vitreous humor values were well correlated to the ones measured in blood $\left(r^{2}=0.658\right)$. Our results showed
\end{abstract}

Electronic supplementary material The online version of this article (doi:10.1007/s00414-011-0581-6) contains supplementary material, which is available to authorized users.

S. Sabatasso $(\bowtie) \cdot$ M. Augsburger $\cdot$ P. Mangin $\cdot$ K. Michaud

University Centre of Legal Medicine, Lausanne-Geneva,

University of Lausanne,

Rue du Bugnon 21,

1011 Lausanne, Switzerland

e-mail: sara.sabatasso@ana.unibe.ch

P. Vaucher

University Centre of Legal Medicine, Lausanne-Geneva,

University of Geneva,

Rue Michel-Servet 1,

1211 Geneva 4, Switzerland

N. Donzé

Institut Cantonal des Hôpitaux Valaisans,

Grand Champsec,

861950 Sion, Switzerland that NT-proBNP can corroborate the pathological findings in cases of natural death related to heart failure, thus, keeping its diagnostic properties passing from the ante mortem to the post mortem setting. Therefore, biologically inactive polypeptides like NT-proBNP seem to be stable enough to be used in forensic medicine as markers of cardiac failure, taking into account the sensitivity and specificity of the test.

Keywords NT-proBNP · Natriuretic peptides · Biomarkers · Heart failure $\cdot$ Forensic autopsy

\section{Introduction}

NT-proBNP is the amino-terminal fragment of the prohormone of BNP (brain natriuretic peptide), which is secreted mainly by atrial or ventricular myocardial cells, essentially in response to ventricular wall stress. The biological actions of BNP include diuresis, vasodilatation, reduction of systemic and regional (renal and cardiac) sympathetic tone, myocardial relaxation, anti-hypertrophic and anti-fibrotic effects and cytoprotection of cardiomyocytes [1].

In clinical practice, BNP and NT-proBNP have been introduced because of their stability in biological specimens and their utility in the management of suspected or established heart failure (diagnosis, prognosis and guided medical treatment) [2-7].

Natriuretic cardiac peptides have also recently been evaluated as biomarkers of cardiac function in medicolegal practice. In the few previous studies on post mortem measurements of these peptides, attention was paid to BNP and ANP (atrial natriuretic peptide) [8]. NT-proBNP seems to be a more reliable biomarker than BNP and ANP because of its greater stability and longer half-life [6,9-11]. 
This was confirmed in one post mortem study, where NTproBNP has been shown to be stable over 24 days in blood and pericardial fluid sampled from bodies with a post mortem interval up to $24 \mathrm{~h}$. In particular, after 24 days of storage at $-20^{\circ} \mathrm{C}$, NT-proBNP concentration in pericardial fluid decreased by no more than $16 \%$ [12]. NT-proBNP could therefore be useful in cases where routine autopsy evaluation is limited (putrefaction, severe trauma, etc.). However, the ability of this biomarker to identify cardiac failure at post mortem examination remains unknown. Therefore, the goal of this study was to estimate the diagnostic accuracy of NT-proBNP in assessing cardiac failure compared to standard post mortem investigations performed in bodies with a post mortem interval comparable to the one selected for the stability study [12], i.e. up to $24 \mathrm{~h}$.

\section{Materials and methods}

\section{Objectives}

Our main objective was to measure sensitivity, specificity, positive and negative predictive values, likelihood ratios of NT-proBNP blood concentration to suspect cardiac failure at post mortem examination. Our secondary objective was to measure correlations between NT-proBNP blood concentrations and those measured in other available fluids (serum, pericardial fluid, vitreous humor). Moreover, we aimed to quantify the eventual influence of age, sex, BMI, other diseases known to modify the NT-proBNP levels and traumatic death on the sensitivity and specificity of NTproBNP blood levels in detecting heart failure.

\section{Studied population}

One hundred sixty-eight out of 210 consecutive medicolegal autopsies performed at the University Centre of Legal Medicine of Lausanne in 2006 were included in this study. To be included, standard investigation procedures (autopsy, histology, toxicology) had to be made and subjects had to be older than 15 years. The post mortem interval ranged from $<12$ to $24 \mathrm{~h}$. Bodies with a post mortem interval $>24 \mathrm{~h}$ were excluded from the study because putrefaction, at any stage, would have rendered impossible or at least very difficult to identify signs of heart failure at autopsy and thus to compare them with the NT-proBNP values measured in various body fluids most of which, moreover, would have been unavailable in case of putrefaction. All autopsies were demanded by legal authorities. The sample reflected the variability of cases seen in forensic post mortem evaluations, as it is illustrated in Table 1.

\section{Reference test}

No gold standard is available in forensic setting. The reference test is the usual procedure used when all available investigations can be performed in usual forensic practice. The diagnosis of heart failure was based on autopsy findings including cardiac cavities dilatation with or without myocardial hypertrophy, visceral congestion of internal organs, lung and/or peripheral oedema. Moreover, the presence of referred or detected pre-existing pathologies known to be causally associated with this syndrome (as coronary artery disease, hypertension, obesity and valvular heart disease) was considered in corroborating the diagnosis of heart failure.

For each case, a complete autopsy was performed, followed by routine histological examination. Details for each case were extracted from the autopsy report and completed by complementary information (sequence of events, circumstances of body discovery, known medical story).

All autopsies were performed by seven physicians, following international recommendations [13]. Three of these physicians were senior residents with at least 10 years of experience in forensic medicine, and 4 of them were residents, always supervised by a senior. All these forensic pathologists were blinded to NT-proBNP lab results.

Two independent forensic pathologists assessed their appreciation of cardiac failure for each case using a fouritem Likert scale (most unlikely, unlikely, very likely, certainly). For cases where experts disagreed, a third forensic pathologist gave his opinion and cases were discussed until a consensus was reached. In their evaluations, these examiners were blinded to NT-proBNP values. Subjects were considered as having suffered from cardiac failure if assessors agreed they were very likely or certainly affected by this condition.

\section{Index test (NT-proBNP)}

Index test was performed after the reference test (prospective). Femoral blood, serum, vitreous humor and pericardial fluid were collected during the autopsy. Serum was obtained by centrifugation of blood samples, immediately after collection. Samples were sent by the forensic examiner to the laboratory and the specimens were stored at $-20^{\circ} \mathrm{C}$ until the time of analysis. Laboratory staff, who reported results, was completely blinded to information regarding cases, except for gender and age. NT-proBNP blood concentrations were measured using a chemiluminescent immunoassay kit (Elecsys 2010 analyser, Roche Diagnostic, Basel, Switzerland; Dimension Xpand plus, Dade Behring, Deerfield, IL, USA). The procedure's test performances were the following: CV inter-assay 9\% (490土 
Table 1 Characteristics of subjects $(n=168)$

\begin{tabular}{|c|c|c|c|}
\hline \multirow[t]{2}{*}{ Characteristics } & \multicolumn{2}{|l|}{ Cardiac failure } & \multirow[b]{2}{*}{$p$ value } \\
\hline & With $n=73$ & Without $n=95$ & \\
\hline Age/gender $(n, \%)$ & & & $<0.001$ \\
\hline Male $<55$ years & $28(38.4 \%)$ & $54(56.8 \%)$ & \\
\hline Male $\geq 55$ years & $26(35.6 \%)$ & $5(5.3 \%)$ & \\
\hline Female $<65$ years & $11(15.1 \%)$ & $30(31.6 \%)$ & \\
\hline Female $\geq 65$ years & $8(11.0 \%)$ & $6(6.3 \%)$ & \\
\hline BMI $\left(\mathrm{kg} / \mathrm{m}^{2}\right)$ & $26.5(5.4)$ & $25.2(5.7)$ & 0.147 \\
\hline Cause of death $(n, \%)$ & & & $<0.001$ \\
\hline \multicolumn{4}{|l|}{ Natural } \\
\hline Cardiovascular system & $31(42.5 \%)$ & $0(0 \%)$ & \\
\hline Other & $10(13.7 \%)$ & $13(13.7 \%)$ & \\
\hline \multicolumn{4}{|l|}{ Violent death } \\
\hline Trauma & $13(17.8 \%)$ & $33(34.7 \%)$ & \\
\hline Other violent deaths & $14(19.2 \%)$ & $45(47.4 \%)$ & \\
\hline Unknown & $5(6.8 \%)$ & $4(4.2 \%)$ & \\
\hline \multicolumn{4}{|l|}{ Autopsy findings } \\
\hline Heart weight; mean (SD), g & $448(104)$ & $348(80)$ & $<0.001$ \\
\hline \multicolumn{4}{|l|}{ Ventricles } \\
\hline Right dilatation $(n, \%)$ & $26(35.6 \%)$ & $18(18.9 \%)$ & 0.015 \\
\hline Right hypertrophy $(n, \%)$ & $29(39.7 \%)$ & $3(3.2 \%)$ & $<0.001$ \\
\hline Left dilatation $(n, \%)$ & $29(39.7 \%)$ & $14(14.7 \%)$ & $<0.001$ \\
\hline Left hypertrophy $(n, \%)$ & $36(49.3 \%)$ & $2(2.1 \%)$ & $<0.001$ \\
\hline \multicolumn{4}{|l|}{ Coronary arteries } \\
\hline Stenosis $>75 \%(n, \%)$ & $18(24.7 \%)$ & $1(1.0 \%)$ & $<0.001$ \\
\hline Thrombosis $(n, \%)$ & $11(15.1 \%)$ & $0(0 \%)$ & $<0.001$ \\
\hline Haemorrhage $(n, \%)$ & $9(12.3 \%)$ & $0(0 \%)$ & $<0.001$ \\
\hline \multicolumn{4}{|l|}{ Macroscopy of heart } \\
\hline Fibrosis $(n, \%)$ & $3(4.1 \%)$ & $1(1.0 \%)$ & 0.198 \\
\hline Signs of infarction $(n, \%)$ & $12(16.4 \%)$ & $5(5.3 \%)$ & 0.017 \\
\hline Valvular insufficiency $(n, \%)$ & $2(2.7 \%)$ & $0(0 \%)$ & 0.105 \\
\hline \multicolumn{4}{|l|}{ Histological findings } \\
\hline Acute ischemia/infarction $(n, \%)$ & $36(49.3 \%)$ & $23(24.2 \%)$ & 0.001 \\
\hline Fibrosis/hypertrophy $(n, \%)$ & $62(84.9 \%)$ & $45(47.4 \%)$ & $<0.001$ \\
\hline Coronary wall thickness $>30 \%(n, \%)$ & $35(47.9 \%)$ & $16(16.8 \%)$ & $<0.001$ \\
\hline Other disease known to increase NT-proBNP & $50(68.5 \%)$ & $38(40 \%)$ & $<0.001$ \\
\hline Degenerative or vascular path CNS $(n, \%)$ & $8(11.0 \%)$ & $5(5.3 \%)$ & 0.171 \\
\hline Pulmonary hypertension $(n, \%)$ & $17(23.3 \%)$ & $8(8.4 \%)$ & 0.007 \\
\hline Pulmonary thromboembolism $(n, \%)$ & $3(4.1 \%)$ & $1(1.0 \%)$ & 0.198 \\
\hline Chronic bronchitis $(n, \%)$ & $15(20.5 \%)$ & $4(4.2 \%)$ & 0.001 \\
\hline Renal vascular pathology $(n, \%)$ & $26(35.6 \%)$ & $15(15.8 \%)$ & 0.003 \\
\hline Liver steatofibrosis $(n, \%)$ & $5(6.8 \%)$ & $8(8.4 \%)$ & 0.705 \\
\hline Severe arteriosclerosis $(n, \%)$ & $41(56.2)$ & $24(25.3 \%)$ & $<0.001$ \\
\hline Blood alcohol positivities ${ }^{\mathrm{a}}(n, \%)$ & $17(23.3 \%)$ & $30(31.6 \%)$ & 0.235 \\
\hline
\end{tabular}

${ }^{\mathrm{a}}$ Samples with $>0.1 \mathrm{~g} / \mathrm{kg}$ blood alcohol concentration measured by Head-Space-GC-FID, were considered as positive

$S D$ standard deviation defined the clinical serum value of $>112 \mathrm{pg} / \mathrm{mL}$ as cut-off also for NT-proBNP blood concentration. To test whether NT-proBNP blood values are correlated to those measured in serum, pericardial fluid and vitreous humor, the same laboratory method was applied to these fluids. 
Other measures

Myocardial specimens for the histological examination were derived from at least five different topographic locations, namely left anterior, left lateral, left posterior, septal and right lateral. They were stained with hematoxylin-eosin. For each case, alcohol concentration was assessed in peripheral blood. Toxicological analyses were performed, when requested, by GC/MS. The presence of common abuse substances was assessed, including cocaine and its metabolites, and the results were compared to published data [14].

\section{Statistical analyses}

Receiver operating curve and area under the curve (AUC) were calculated for different NT-proBNP values. In the clinical setting, the reference ranges for NT-proBNP vary depending on the assay method used and the nature of the control population $[15,16]$. A suggested "normal" range for NT-proBNP is $68-112 \mathrm{pg} / \mathrm{mL}[5,16]$. Thus, we chose a cut-off value of $>112 \mathrm{pg} / \mathrm{mL}$ to define NT-proBNP as positive or negative. Sensitivity, specificity, positive and negative predictive values, positive and negative likelihood ratios were then given with $95 \%$ confidence intervals $(95 \%$ CI). Sensitivity and specificity were calculated for subpopulations (age and sex, BMI, presence of renal, pulmonary and central nervous system pathology, signs of trauma). Linear regression analysis was used to define association between NT-proBNP concentrations in blood and in other biological fluids. Transformations were used to test other associations than linear correlations, when required. $R^{2}$ from the regression was calculated to estimate the strength of the association between blood and other body fluids. Analyses were conducted using STATA 10.1 (College Station, TX 77845 USA).

\section{Results}

From 210 consecutive autopsies performed from January to December 2006, 168 were included in the analysis. Criteria for exclusions are given in Fig. 1.

The two initial assessors agreed on the presence of cardiac failure from the results given in the autopsy report for 135 cases (80.4\%) showing a substantial agreement $(\mathrm{kappa}=0.61)$ using Landis and Koch's interpretation of kappa values [17]. Total agreement among the three experts was easily reached for the remaining 33 cases $(19.6 \%)$. Cardiac failure was considered as certain for 27 cases $(15.9 \%)$, very likely for 46 cases $(27.4 \%)$, unlikely for 46 cases $(27.4 \%)$ and most unlikely for 49 cases $(29.2 \%)$.

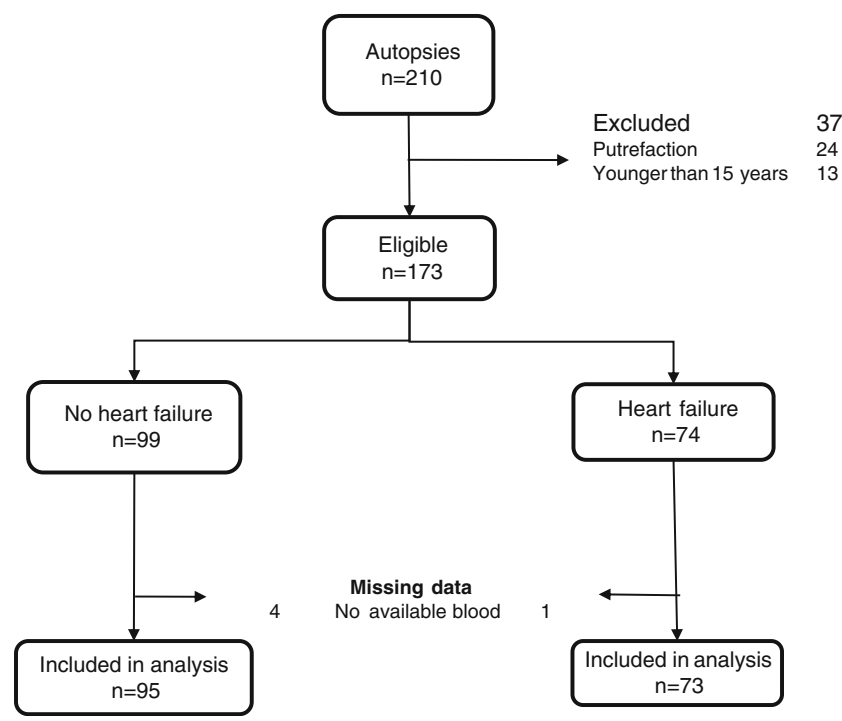

Fig. 1 Flow chart indicating the studied population and the excluded cases

Characteristics of cases with or without heart failure and levels of significance ( $p$ values) are reported in Table 1. Subjects with heart failure were older than those without this condition and they were more often of male gender. Among them, death was more recurrently natural, related to cardiovascular diseases. Furthermore, subjects with heart failure were more likely to present other diseases known to influence NT-proBNP values $(p<0.001)$. Finally, victims who died from traumatic causes were two times less likely to suffer from heart failure than other deceased $(28.3 \%$ vs. $49.2 \%)$.

\section{Validity of NT-proBNP for predicting heart failure}

We verified that NT-proBNP blood concentration could be used instead of serum in forensic settings (Fig. 3a). Concentrations were logged and regression was used to compare findings. In forensic settings, $58.5 \%$ of the variance of blood values can be explained from serum values using the following equation: NT-proBNP ${ }_{\text {serum }}=e^{0.91 \cdot \ln (\mathrm{NT} \text {-proBNPblood })+1.1}$. Therefore, the standard serum cut-off value of $>112 \mathrm{pg} / \mathrm{mL}$ of NT-proBNP is equivalent to $>220 \mathrm{pg} / \mathrm{mL}$ of NT-proBNP blood concentration for our sample.

Using a standard cut-off value of $>220 \mathrm{pg} / \mathrm{mL}$ of NTproBNP ${ }_{\text {blood }}$ to define heart failure, $37 / 73$ (50.7\%) subjects with this condition were detected positive (sensitivity), whereas 26/95 (72.6\%) individuals without heart failure had a NT-proBNP blood $\leq 220 \mathrm{pg} / \mathrm{mL}$ (specificity).

Area under the receiving operator curve (Fig. 2) was of $65.4 \%$, with a confidence interval of $95 \%$ (CI 95\%), from 57.1 to 73.7. An optimal diagnosis test would have an area under the curve of $100 \%$, whereas a test which has no predictive diagnosis ability would have an area of $50 \%$ 
Fig. 2 Receiving operator's curve illustrating NT-proBNP's ability to detect heart failure

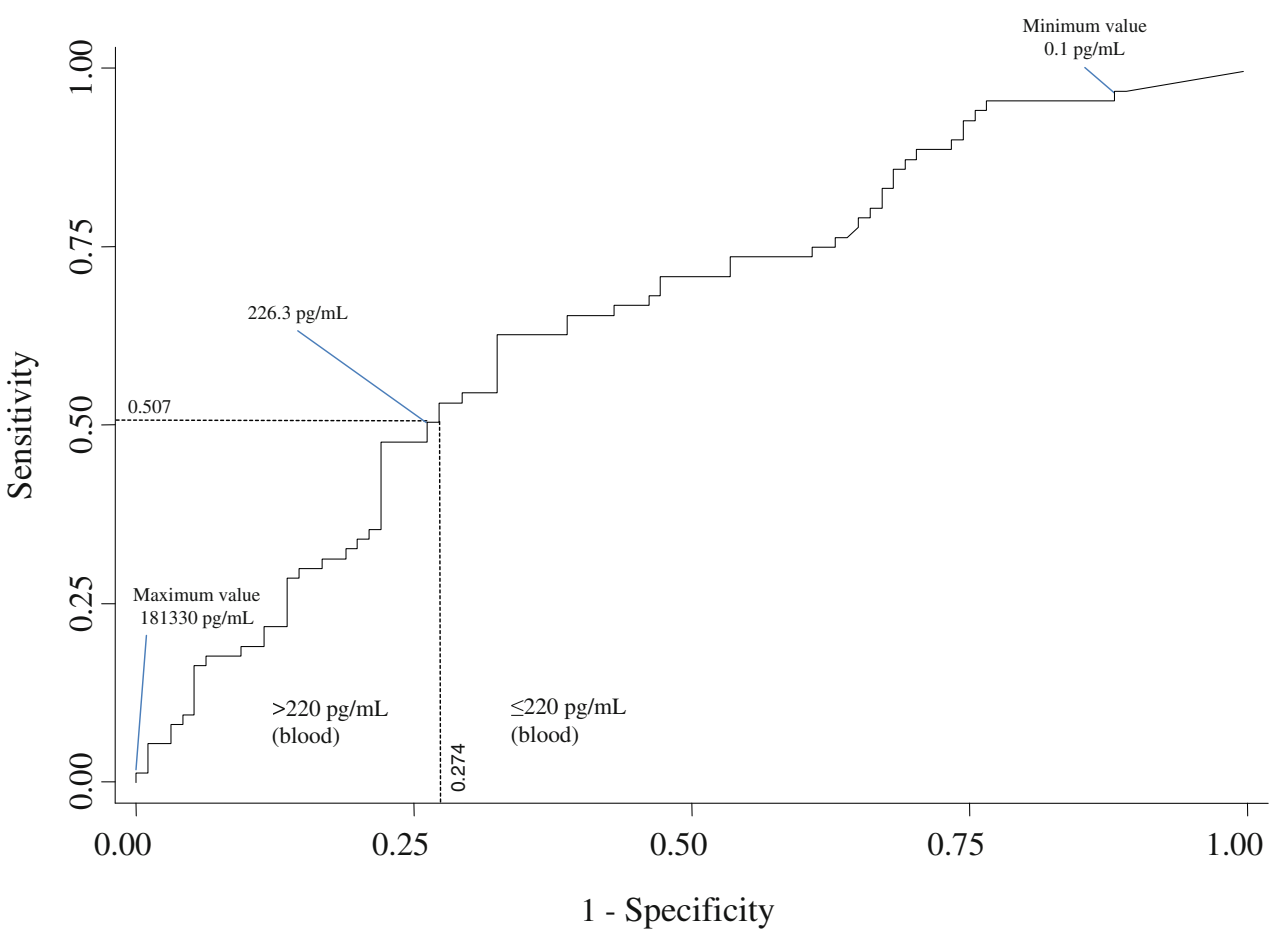

[18]. When including only cases for which heart failure was either considered certain $(n=27)$, or most unlikely $(n=49)$ the area under the receiving operator curve was of 67.8 (CI $95 \% 55.1$ to 80.5$)$. Sensitivity, specificity, predictive values and likelihood ratios of NT-proBNP for detecting heart failure are given with CI 95\% in Table 2.

Correlation of NT-proBNP values in different body fluids

Body fluids other than blood were available for 89 autopsies. Correlation was highest between blood and vitreous humor $\left(R^{2}=0.658\right.$; CI $95 \% 0.52$ to 0.76$)$, then between blood and pericardial fluid $\left(R^{2}=0.397\right.$; CI $95 \%$ 0.21 to 0.56$)$. $R^{2}$ corresponds to the proportion of variance explained by the correlated variable (identical to the squared Pearson's correlation value) and ranges from 0 to 1 , where 1 is a perfect correlation. We also observed that

Table 2 Validity of NT-proBNP to detect heart failure at post mortem examination

\begin{tabular}{lcl}
\hline & Values & CI $95 \%$ \\
\hline Sensitivity & $50.7 \%$ & $38.8 \%$ to $62.5 \%$ \\
Specificity & $72.6 \%$ & $62.4 \%$ to $81.0 \%$ \\
Predictive values & & \\
Positive & $58.7 \%$ & $45.6 \%$ to $70.8 \%$ \\
Negative & $65.7 \%$ & $55.7 \%$ to $74.5 \%$ \\
Likelihood ratio & & 1.2 to 2.8 \\
Positive & 1.9 & 0.53 to 0.86 \\
Negative & 0.68 & \\
\hline
\end{tabular}

NT-proBNP values were most often much higher in pericardial fluid than in other fluids (Fig. 3b, c).

Sensitivity and specificity of NT-proBNP

for sub-populations

Sensitivity and specificity of NT-proBNP across studied sub-populations are given in Table 3. BMI and presence of other diseases known to influence NT-proBNP levels do not seem to influence sensitivity and specificity of the test (Table 3). We, however, observed a lower specificity for subjects who died from natural events, compared to those who died from traumatic causes (23.1 vs. 82.1). There was also a trend towards age and gender differences with higher specificity for older men compared to lower specificity for older women (100 vs. 16.7).

\section{Discussion}

We have investigated the ability of NT-proBNP blood values to detect heart failure at post mortem examination by measuring its sensitivity, specificity, positive and negative predictive values and likelihood ratios as well.

NT-proBNP blood concentrations can corroborate the pathological findings in cases of natural death related to heart failure, as demonstrated by the substantial agreement (kappa $=0.61)$ reached among the three experts who evaluated the autopsy reports. This is an important finding, which shows that NT-proBNP retains its diagnostic value, already well-established in the clinical setting [2-4, 7, 19- 
Fig. 3 Correlations between NT-proBNP blood values and those measured in other body fluids

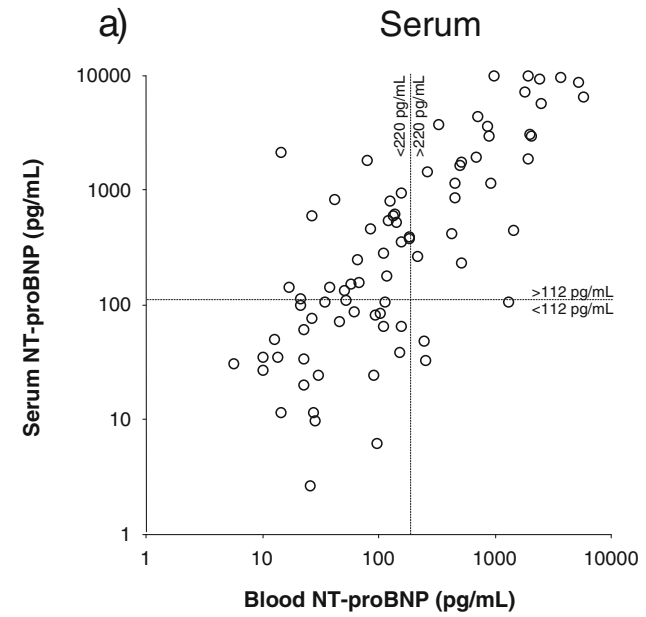

b) Vitreous humor

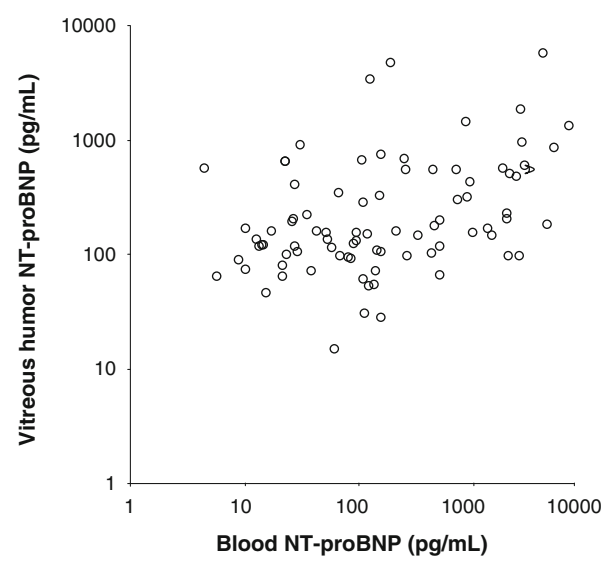

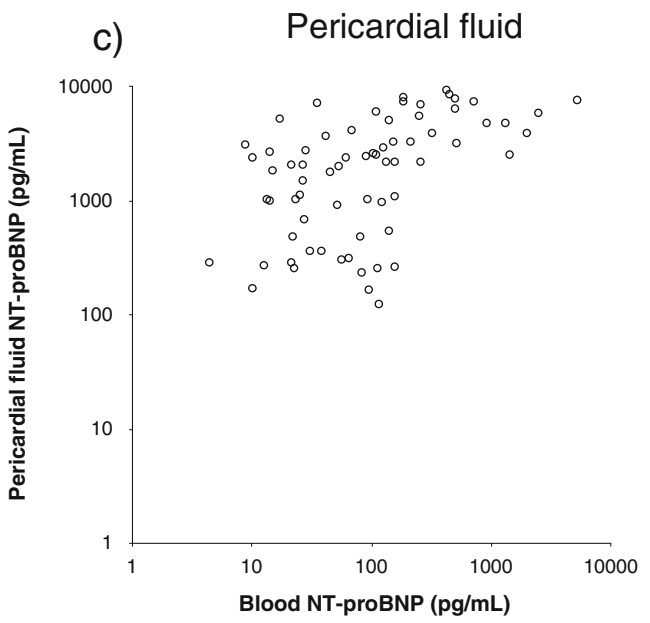

24]. Combining our observations with the results of a previous study demonstrating the stability of this biomarker in post mortem samples [12], we have shown-for the first time up to now-that a biomarker keeps its diagnostic features unaltered passing from the ante mortem to the post mortem setting. This differentiates NT-proBNP from other markers of cardiac pathologies, whose diagnostic validity using post mortem material is controversial. For example,
Table 3 Sensitivity and specificity of NT-proBNP to detect heart failure for different sub-populations

${ }^{a}$ Concerns pathologies known to influence NT-proBNP values (renal, pulmonary and central nervous system pathologies)

\begin{tabular}{lcc}
\hline & Sensitivity & Specificity \\
\hline $\begin{array}{l}\text { All cases } \\
\text { Age/gender }\end{array}$ & $50.7(38.8$ to 62.5$)$ & $72.6(62.4$ to 81.0$)$ \\
Men under 55 years & $39.3(22.1$ to 59.3$)$ & $85.2(72.3$ to 92.9$)$ \\
Men 55 years or over & $53.8(33.7$ to 72.9$)$ & 100 (46.3 to 100$)$ \\
Women under 65 years & $45.5(18.1$ to 75.4$)$ & $56.7(37.7$ to 74.0$)$ \\
Women 65 years or over & $87.5(46.7$ to 99.3$)$ & $16.7(0.1$ to 63.5$)$ \\
BMI & $51.9(38.0$ to 65.5$)$ & $73.3(61.7$ to 82.6$)$ \\
$\leq 30 \mathrm{~kg} / \mathrm{m}^{2}$ & $47.4(25.2$ to 70.5$)$ & $70.0(45.7$ to 87.2$)$ \\
$>30 \mathrm{~kg} / \mathrm{m}^{2}$ & & $65.8(48.6$ to 79.9$)$ \\
Pathologies & $58.0(43.3$ to 71.5$)$ & $77.2(63.8$ to 86.8$)$ \\
With other pathologies & \\
Without other pathologies & $\mathrm{a}$ & \\
Cause of death & $34.8(17.2$ to 57.2$)$ & 23.1 (6.2 to 54.0$)$ \\
Natural deaths & $46.3(31.0$ to 62.4$)$ & 82.1 (71.4 to 89.5$)$ \\
Violent death with trauma & $59.3(39.0$ to 77.0$)$ & \\
\hline
\end{tabular}


troponins (I and $\mathrm{T}$ ) are known to be the preferred markers for the laboratory diagnosis of myocardial infarction in the clinical setting $[25,26]$. Conversely, in the post mortem context, not only they are not specific for myocardial injury, as they increase also in other conditions [27, 28], but also their levels are influenced by the post mortem interval [2830]. Some authors even pointed out that post mortem blood is an unsuitable sample to measure cardiac troponins [31].

Our results are in accordance with clinical data regarding the factors influencing the increase of NT-proBNP levels $[1-3,5,6]$. Likewise, subjects who were diagnosed with heart failure at post mortem examination were shown to be more likely to present other diseases known to influence NT-proBNP values, as renal, pulmonary and central nervous system pathologies, thus still confirming the clinical data. In fact, it is known that the levels of natriuretic peptides may rise in some pathological situations, such as renal pathologies, disorders associated with diastolic dysfunction, primary pulmonary hypertension, cor pulmonale, pulmonary embolism, congenital heart diseases and arrhythmogenic right-ventricular dysplasia [3]. This can also explain why we observed a lower specificity of NTproBNP to detect heart failure for subjects who died from natural causes compared to those who died from traumatic events. Our finding that victims who died from traumatic causes were two times less likely to suffer from heart failure than other deceased $(28.3 \%$ vs. $49.2 \%)$ can be related to the short agonal period which characterised most of these traumatic deaths.

In this study, we have also evaluated the correlations of NT-proBNP blood values with different body fluids, namely serum, pericardial fluid and vitreous humor. We found out that the correlation was highest between blood and vitreous humor $\left(R^{2}=0.658\right)$, and then between blood and pericardial fluid $\left(R^{2}=0.397\right)$. This is in discordance with the results of a previous study [12], which found a weak correlation with vitreous humor. In the mentioned study, however, values were not transformed before testing correlations. Our log-transformed values confirm the vitreous humor as a good substrate for post mortem biochemical testing [32-37]. Furthermore, the ascertainment that blood levels correlate well with those of vitreous humor and pericardial fluid is important, because in forensic practice, the latter body fluids might not be available, like in putrefied corpses. This means that in such cases where the autopsy investigation is obviously limited, an increased NT-proBNP blood value may give indication about the natural origin of death.

Beside this, we observed that NT-proBNP values were most often much higher in pericardial fluid than in other fluids. A possible explanation for this is that biochemical markers reach the pericardial fluid through passive diffusion and ultrafiltration due to pressure gradient, so they are detectable in higher concentration in pericardial fluid before they reach the other fluids [38-41].

In conclusion, our study shows that NT-proBNP has similar diagnostic properties in the post mortem setting as it has in the clinical one. However, a systematic dosage of this biomarker in body fluids of fresh corpses is unjustified because it has a low validity (with a sensitivity of $50.7 \%$ and a specificity of $72.6 \%$ ) to detect heart failure. This is not due to an inappropriate choice of a cut-off point set at $220 \mathrm{pg} / \mathrm{mL}$, as the area under the receiver operating curve also shows low predictive ability $(\mathrm{AUC}=65.4 \%)$. For this reason, it is suggested to use the standard macro- and microscopical methods to detect heart failure at post mortem examination, eventually validated by immunohistochemical studies [42, 43]. Conversely, in putrefied bodies, where autopsy is limited, increased NT-proBNP blood levels can give indication about the (natural) manner of death, in the absence of traumatic lesions during radiological examination.

\section{Limitations}

The study does not have enough power to truly identify clinically significant differences in sensitivity or specificity in sub-populations. Sensitivity and specificity of the reference test we used (autopsy findings) remain unknown. Linearity of NT-proBNP concentrations in vitreous humor and pericardial fluid was not tested.

Open Access This article is distributed under the terms of the Creative Commons Attribution Noncommercial License which permits any noncommercial use, distribution, and reproduction in any medium, provided the original author(s) and source are credited.

\section{References}

1. Munagala VK, Burnett JC Jr, Redfield MM (2004) The natriuretic peptides in cardiovascular medicine. Curr Probl Cardiol 29:707-769

2. Clerico A, Emdin M (2004) Diagnostic accuracy and prognostic relevance of the measurement of cardiac natriuretic peptides: a review. Clin Chem 50:33-50

3. de Lemos JA, McGuire DK, Drazner MH (2003) B-type natriuretic peptide in cardiovascular disease. Lancet 362:316-322

4. Hall C (2004) Essential biochemistry and physiology of (NT-pro) BNP. Eur J Heart Fail 6:257-260

5. Richards AM, Nicholls MG, Yandle TG et al (1998) Plasma Nterminal pro-brain natriuretic peptide and adrenomedullin: new neurohormonal predictors of left ventricular function and prognosis after myocardial infarction. Circulation 97:1921-1929

6. Omland T, Aakvaag A, Bonarjee VV et al (1996) Plasma brain natriuretic peptide as an indicator of left ventricular systolic function and long-term survival after acute myocardial infarction. Comparison with plasma atrial natriuretic peptide and N-terminal proatrial natriuretic peptide. Circulation 93:1963-1969 
7. Schulz H, Langvik TA, Lund Sagen E et al (2001) Radioimmunoassay for $\mathrm{N}$-terminal probrain natriuretic peptide in human plasma. Scand J Clin Lab Invest 61:33-42

8. Zhu BL, Ishikawa $T$, Michiue $T$ et al (2007) Postmortem pericardial natriuretic peptides as markers of cardiac function in medico-legal autopsies. Int J Legal Med 121:28-35

9. Pfister R, Scholz M, Wielckens K et al (2004) Use of NT-proBNP in routine testing and comparison to BNP. Eur J Heart Fail 6:289-293

10. Kragelund C, Gronning B, Kober L et al (2005) N-Terminal proB-type natriuretic peptide and long-term mortality in stable coronary heart disease. N Engl J Med 352:666-675

11. Nowatzke WL, Cole TG (2003) Stability of N-terminal pro-brain natriuretic peptide after storage frozen for one year and after multiple freeze-thaw cycles. Clin Chem 49:1560-1562

12. Michaud K, Augsburger M, Donzé N et al (2008) Evaluation of postmortem measurement of NT-proBNP as a marker for cardiac function. Int J Legal Med 122:415-420

13. Recommendation no. R (99) 3 of the Committee of Ministers to member states on the harmonization of medico-legal autopsy rules (2000) Forensic Sci Int 111:5-58

14. Winek CL, Wahba WW, Winek CL Jr et al (2001) Drug chemical blood level data 2001. Forensic Sci Int 122:107-123

15. Jensen KT, Carstens J, Ivarsen P et al (1997) A new, fast and reliable radioimmunoassay of brain natriuretic peptide in human plasma. Reference values in healthy subjects and in patients with different diseases. Scand J Clin Lab Invest 57:529-540

16. Cowie MR, Jourdain P, Maisel A et al (2003) Clinical applications of B-type natriuretic peptide (BNP) testing. Eur Heart J 24:1710-1718

17. Landis JR, Koch GG (1977) The measurement of observer agreement for categorical data. Biometrics 33:159-174

18. Zweig MH, Campbell G (1993) Receiver-operating characteristic (ROC) plots: a fundamental evaluation tool in clinical medicine. Clin Chem 8:561-577

19. Seino Y, Ogawa A, Yamashita T et al (2004) Application of NTproBNP and BNP measurements in cardiac care: a more discerning marker for the detection and evaluation of heart failure. Eur J Heart Fail 6:295-300

20. Groenning BA, Nilsson JC, Sondergaard L et al (2002) Detection of left ventricular enlargement and impaired systolic function with plasma N-terminal pro brain natriuretic peptide concentrations. Am Heart J 143:923-929

21. Schelton RJ, Clark AL, Goode K et al (2006) The diagnostic utility of N-terminal pro-B-type natriuretic peptide for the detection of major structural heart disease in patients with atrial fibrillation. Eur Heart J 27:2353-2361

22. Mikkelsen KV, Bie P, Møller JE et al (2006) The diagnostic utility of $\mathrm{N}$-terminal pro-B-type natriuretic peptide for the detection of major structural heart disease in patients with atrial fibrillation. Int J Cardiol 110:324-333

23. Goode KM, Clark AL, Cleland JGF (2008) Ruling out heart failure in primary care: the cost-benefit of pre-screening using NTproBNP and QRS width. Int J Cardiol 130:426-437

24. Talwar S, Squire IB, Davies JE et al (1999) Plasma N-terminal pro-brain natriuretic peptide and the ECG in the assessment of left-ventricular systolic dysfunction in a high risk population. Eur Heart J 20:1736-1744

25. Apple FS, Jesse RL, Newby LK et al (2007) National academy of clinical biochemistry and IFCC committee for standardization of markers of cardiac damage laboratory medicine practice guidelines: analytical issues for biochemical markers of acute coronary syndromes. Clin Chem 53:547-551
26. Morrow DA, Cannon CP, Jesse RL (2007) National academy of clinical biochemistry laboratory medicine practice guidelines: clinical characteristics and utilization of biochemical markers in acute coronary syndromes. Clin Chem 53:552-574

27. Ellingsen CL, Hetland Ø (2004) Serum concentrations of cardiac troponin $\mathrm{T}$ in sudden death. Am J Forensic Med Pathol 25:213215

28. Zhu BL, Ishikawa T, Michiue T et al (2006) Postmortem cardiac troponin $\mathrm{T}$ levels in the blood and pericardial fluid. Part 2: analysis for application in the diagnosis of sudden cardiac death with regard to pathology. Leg Med (Tokyo) 8:94-101

29. Peter J, Kirchner A, Kuhlisch E et al (2006) The relevance of the detection of troponins to the forensic diagnosis of cardiac contusion. Forensic Sci Int 160:127-133

30. Vargas SO, Grudzien C, Tanasijevic MJ (2008) Postmortem cardiac troponin-I levels predict intramyocardial damage at autopsy. J Thromb Thrombolysis 26:132-137

31. Davies SJ, Gaze DC, Collinson PO (2005) Investigation of cardiac troponins in postmortem subjects: comparing antemortem and postmortem levels. Am J Forensic Med Pathol 26:213-215

32. Ingham AL, Byard RW (2009) The potential significance of elevated vitreous sodium levels at autopsy. J Forensic Leg Med $16: 437-440$

33. Fucci N, De Giovanni N, De Giorgio F et al (2006) An evaluation of the Cozart RapiScan system as an on-site screening tool for drugs of abuse in a non-conventional biological matrix: vitreous humor. Forensic Sci Int 156:102-105

34. Teixeira HM, Reis F, Proença P et al (2004) Vitreous humour as a complementary sample to blood for the detection/confirmation of diazepam: ante-mortem and post-mortem studies in an animal model. Hum Exp Toxicol 23:571-577

35. De Letter EA, Piette MH (1998) Can routinely combined analysis of glucose and lactate in vitreous humour be useful in current forensic practice? Am J Forensic Med Pathol 19:335-342

36. De Letter EA, De Paepe P, Clauwaert KM et al (2000) Is vitreous humour useful for the interpretation of 3,4-methylenedioxymethamphetamine (MDMA) blood levels? Experimental approach with rabbits. Int J Leg Med 114:29-35

37. Winek CL, Esposito FM (1981) Comparative study of ethanol levels in blood versus bone marrow, vitreous humor, bile and urine. Forensic Sci Int 17:27-36

38. Luna A, Carmona A, Villanueva E (1983) The postmortem determination of $\mathrm{CK}$ isozymes in the pericardial fluid in various causes of death. Forensic Sci Int 22:23-30

39. Perez-Cárceles MD, Osuna E, Vieira DN et al (1995) Biochemical assessment of acute myocardial ischaemia. J Clin Pathol 48:124128

40. Gibson AT, Segal MB (1978) A study of the composition of pericardial fluid, with special reference to the probable mechanism of fluid formation. J Physiol 277:367-377

41. Gibson AT, Segal MB (1978) A study of the routes by which protein passes from the pericardial cavity to the blood in rabbits. J Physiol 280:423-433

42. Fracasso T, Karger B, Pfeiffer $H$ et al (2009) Immunohistochemical identification of prevalent right ventricular ischemia causing right heart failure in cases of pulmonary fat embolism. Int J Leg Med. doi:10.1007/s00414-009-0382-3

43. Fracasso T, Pfeiffer H, Sauerland C et al (2010) Morphological identification of right ventricular failure in cases of fatal pulmonary thromboembolism. Int J Leg Med. doi:10.1007/ s00414-010-0486-9 